\title{
Associations of behavioural, psychosocial and socioeconomic factors with over- and underweight among German adolescents
}

\author{
Rafael T. Mikolajczyk', Matthias Richter ${ }^{2}$ \\ ${ }^{1}$ Department of Public Health Medicine, School of Public Health, University of Bielefeld, Bielefeld, Germany \\ ${ }^{2}$ Department of Prevention \& Health Promotion, School of Public Health, University of Bielefeld, Bielefeld, Germany
}

Submitted: 26 December 2007; Revised: 17 April 2008; Accepted: 12 May 2008

Summary

Objectives: The prevalence of overweight and obesity has dramatically increased in western societies. This paper examines behavioural, psychosocial and socioeconomic factors associated with overweight and underweight among adolescents in Germany.

Methods: Data from the German part of the 2001/02 Health Behaviour in School-aged Children (HBSC) survey, composed of 5,650 respondents aged 11 to 17 years were analysed. Body mass index (BMI) was calculated based on self-reported weight and height. The overweight category was defined as BMI within or above the 90th percentile of specific BMI values for gender and age in the German national sample. The underweight category was defined as BMI within or below the 10th percentile of this sample. A multinomial logistic regression model was used to investigate the association between behavioural, psychosocial and socioeconomic factors and BMI categories.

Results: $9.5 \%$ of the boys and $5.4 \%$ of the girls were classified as overweight. The prevalence of underweight was $12.6 \%$ among boys and $19.1 \%$ among girls. Several factors were associated with over- and/or underweight in the bivariate analysis, showing different patterns for gender and BMI categories. In the multivariable model only low family affluence, high sedentary behaviour, and being bullied (for girls only) remained positively associated with being overweight. Being underweight was negatively associated with higher age and low parental occupation; it differed also by region.

Conclusion: Despite several variables being associated with overweight and underweight in bivariate models, only three factors remained associated with overweight in multivariable analysis. Other considered variables did not have independent associations with the outcome, but still could be included in respective causal pathways. Our results suggest that preventive strategies focussing on students of low socio-economic status and the avoidance of sedentary behaviours could help to address issues of overweight and obesity.

Keywords: Overweight - Underweight - Behaviour - Psychosocial HBSC - Germany.

The general increase in the prevalence of overweight and obesity among children and adolescents has become a key threat for public health in industrialised countries ${ }^{1,2}$. Current research shows that overweight in childhood and adolescence is associated with several individual and social determinants: physical inactivity ${ }^{3-8}$, consumption of sweets and soft drinks ${ }^{9}$, lack of parental support, stress associated with unsatisfactory outcomes in school and/or being bullied ${ }^{6,10,11}$, and low socioeconomic status ${ }^{12-15}$. So far, many studies dealing with correlates of overweight in children have focused on single or very limited numbers of associations. In addition, studies frequently compare overweight children with all others, discounting possible differences between normal weight and underweight children. The aims of this study were 1) to assess what behavioural, psychosocial and socioeconomic factors are associated with weight problems before and after mutual adjustment of the factors, and 2) to analyse whether the associations differ by gender or age. 


\section{Methods}

\section{Sample}

Data were obtained from the German part of the 2001/02 Health Behaviour in School-aged Children (HBSC) study, a multinational study that was conducted in collaboration with the World Health Organization ${ }^{16,17}$. The total sample included 5,650 students ( $49.3 \%$ boys, $50.7 \%$ girls) aged $11-17$ years (mean 13.5 years; SD 1.71). Data were collected by means of a standardised questionnaire. Teachers administered the questionnaires in the classroom. Students were included in the study if they volunteered to participate and if their parents had also signed an informed consent. Further details of the German HBSC study can be found elsewhere ${ }^{18}$.

\section{Body-Mass Index}

Body-Mass-Index (BMI) was calculated from self-reported weight and height $\left(\mathrm{kg} / \mathrm{m}^{2}\right)$. The age- and gender-specific BMI cut-off points for the German population were used to define subjects as underweight ( $\leq 10$ th percentile), normal weight and overweight $(\geq 90 \text { th percentile })^{19}$. While most variables had a very low proportion of missing responses, 7-8\% of the weight and/or height responses were missing; these responses were included in a separate category for the analysis of missing values.

\section{Behavioural, psychosocial and socioeconomic factors}

The following variables were analysed (categories are indicated in parentheses).

Socioeconomic factors: family structure (living with both parents, single parent family, step-family, and other); parental occupation (high, middle and low status of the head of the household); family affluence was measured with a four item scale $^{20,21}$ : number of vacations during the past year, family car ownership, number of computers in the household, and whether children had their own bedroom (high, middle and low).

Psychosocial factors: Parental support was measured with four items: "How easy is it for you to talk to the following people about things that really bother you?" a) father, b) mother, c) stepfather, d) stepmother" (Students who reported that it was "difficult" or "very difficult" to talk to any of the named persons were classified as having low support); classmate support was measured with a three item scale: "The students in my class(es) enjoy being together", "Most of the students in my class(es) are kind and helpful", "Other students accept me as I am" (high, low); school adjustment was assessed with a composite of three items "How do you feel about school at present?", "In your opinion, what does your teacher(s) think about your school performance compared to your class- mates?", and "How pressured do you feel by the schoolwork you have to do? (high, low); number of friends of the same and the opposite sex (more than two friends, two or less).

Behavioural factors: smoking (less than once a week, at least once a week); physical activity in the past week and in a typical week (2-7 days a week, 0-1.5 days a week $)^{22}$; sedentary behaviour: composite score of three items of hours spent watching television, using a computer, doing homework (low, high); consumption of fruits/vegetables and sweets/soft drinks in a typical week (low, high); having breakfast at home on school

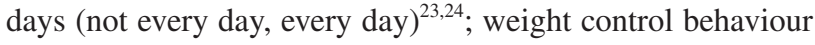
(yes, no) being bullied at school in the past two months (rarely/never, more than two times a month).

\section{Statistical Analysis}

When no explicit rules for calculating scores from multiple variables with similar content existed, Categorical Principal

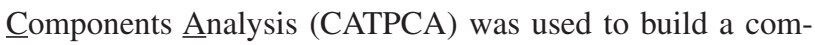
posite index. CATPCA is a non-parametric version of factor analysis suitable for analysis of categorical (ordinal) variables $^{25-27}$. The obtained scores were dichotomised at median or into tertiles. When missing values exceeded the level of $10 \%$, they were included in the analysis as a separate category. Bivariate analyses were performed separately for boys and girls and for the subgroup with missing values for weight or height. Thereafter, all independent variables were included in a multinomial logistic regression model together with interactions between them and gender or grade. Backward selection was performed to obtain a reduced model, including only terms significant at $\mathrm{p}<0.05$.

\section{Results}

\section{Prevalence of overweight and underweight and patterns of missing information on BMI}

A lower proportion of girls (5.4\%) compared to boys (9.5\%) were classified as overweight ( $\geq 90$ th percentile) and $19.1 \%$ of the girls and $12.6 \%$ of the boys were classified as underweight ( $\leq 10$ th percentile). The proportion of missing BMI information was slightly higher in girls than in boys and for children in lower grades; it also differed strongly across regions (Table 1).

\section{Factors associated with over- and underweight in bivariate} analysis

Several of the analysed covariates were significantly $(\mathrm{p}<0.05)$ associated with weight categories, but the pattern differed by gender and for underweight/overweight (Table 1). Low paren- 
Table 1. Percentages of children with overweight, underweight or missing BMI information for different characteristics (separate analyses for both genders for weight categories, normal weight is not presented but is composite to $100 \%$, for missing BMI composite to $100 \%$ is non-missing).

\begin{tabular}{|c|c|c|c|c|c|c|c|c|c|c|}
\hline & \multicolumn{4}{|c|}{$\begin{array}{l}\text { Boys } \\
N=2,433\end{array}$} & \multicolumn{4}{|c|}{$\begin{array}{l}\text { Girls } \\
N=2,445\end{array}$} & \multicolumn{2}{|c|}{ Total sample } \\
\hline & $\begin{array}{l}\text { Under- } \\
\text { weight }\end{array}$ & p-value* & $\begin{array}{l}\text { Over- } \\
\text { weight }\end{array}$ & p-value* & $\begin{array}{l}\text { Under- } \\
\text { weight }\end{array}$ & p-value* & $\begin{array}{l}\text { Over- } \\
\text { weight }\end{array}$ & p-value* & $\begin{array}{l}\text { Missing } \\
\text { BMI }\end{array}$ & p-value\# \\
\hline Total & 12.6 & & 9.5 & & 19.1 & & 5.4 & & 13.7 & \\
\hline Grade & & $<0.05$ & & & & $<0.05$ & & & & $<0.05$ \\
\hline 5 (11-year olds) & 15.8 & & 8.2 & & 22.2 & & 5.3 & & 18.7 & \\
\hline 7 (13-year olds) & 13.4 & & 10.6 & & 20.3 & & 5.8 & & 11.5 & \\
\hline 9 (15-year olds) & 8.0 & & 9.8 & & 14.8 & & 5.0 & & 9.8 & \\
\hline Region/Municipality & & & & & & $<0.05$ & & & & $<0.05$ \\
\hline Berlin (B) & 13.7 & & 11.4 & & 16.4 & & 5.3 & & 5.8 & \\
\hline Hesse (HE) & 11.6 & & 6.7 & & 20.4 & & 5.8 & & 17.1 & \\
\hline $\begin{array}{l}\text { Northrhine-Westphalia } \\
\text { (NRW) }\end{array}$ & 13.4 & & 9.9 & & 20.7 & & 5.3 & & 15.8 & \\
\hline Saxony (SA) & 9.4 & & 9.7 & & 12.6 & & 4.9 & & 4.0 & \\
\hline \multicolumn{11}{|l|}{ Socioeconomic factors } \\
\hline Family structure & & & & & & & & $<0.05$ & & \\
\hline both parents & 12.3 & & 9.2 & & 18.8 & & 4.7 & & 14.0 & \\
\hline Single parent & 11.1 & & 11.5 & & 18.0 & & 8.6 & & 12.8 & \\
\hline step family & 15.1 & & 10.5 & & 22.8 & & 5.1 & & 11.8 & \\
\hline Other & 20.0 & & 5.0 & & 20.8 & & 8.3 & & 8.3 & \\
\hline Parental occupation+ & & $<0.05$ & & $<0.05$ & & & & $<0.05$ & & $<0.05$ \\
\hline High & 16.1 & & 6.2 & & 21.9 & & 4.8 & & 9.8 & \\
\hline Middle & 11.8 & & 8.0 & & 19.6 & & 4.3 & & 13.4 & \\
\hline Low & 10.8 & & 11.8 & & 16.9 & & 6.9 & & 13.8 & \\
\hline Family affluence+ & & & & $<0.05$ & & & & $<0.05$ & & \\
\hline High & 13.6 & & 6.8 & & 21.6 & & 2.6 & & 12.1 & \\
\hline Middle & 13.3 & & 9.8 & & 18.7 & & 6.0 & & 14.2 & \\
\hline Low & 9.7 & & 13.1 & & 16.7 & & 7.6 & & 14.7 & \\
\hline
\end{tabular}

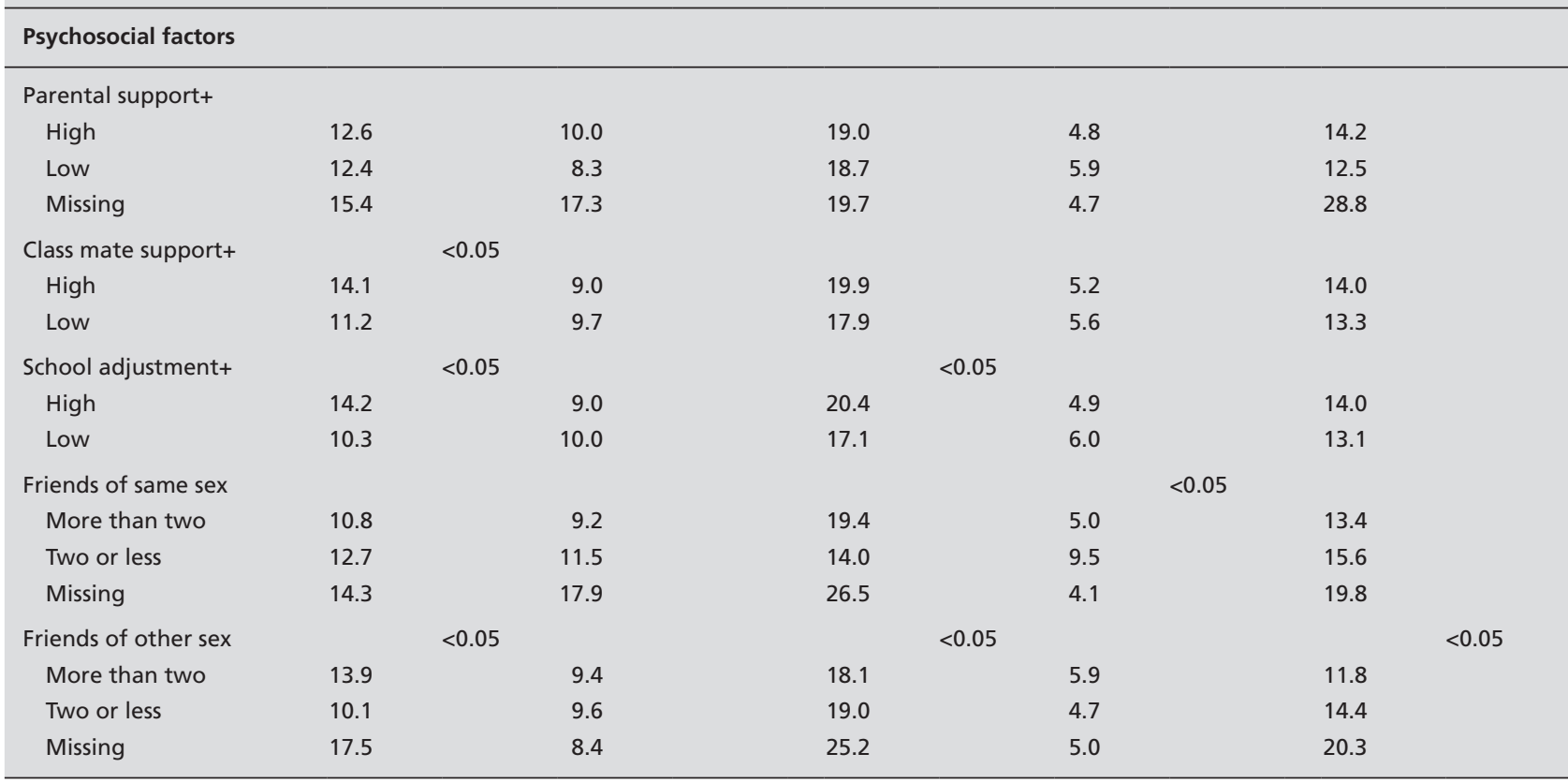


Table 1 continued.

\begin{tabular}{|c|c|c|c|c|c|c|c|c|c|c|}
\hline & \multicolumn{4}{|c|}{$\begin{array}{l}\text { Boys } \\
N=2,433\end{array}$} & \multicolumn{4}{|c|}{$\begin{array}{l}\text { Girls } \\
N=2,445\end{array}$} & \multicolumn{2}{|c|}{ Total sample } \\
\hline & $\begin{array}{l}\text { Under- } \\
\text { weight }\end{array}$ & p-value* & $\begin{array}{l}\text { Over- } \\
\text { weight }\end{array}$ & p-value* & $\begin{array}{l}\text { Under- } \\
\text { weight }\end{array}$ & p-value* & $\begin{array}{l}\text { Over- } \\
\text { weight }\end{array}$ & p-value* & $\begin{array}{l}\text { Missing } \\
\text { BMI }\end{array}$ & p-value\# \\
\hline \multicolumn{11}{|l|}{ Behavioural factors } \\
\hline \multicolumn{11}{|l|}{ Smoking } \\
\hline Less than once a week & 13.1 & & 9.4 & & 19.6 & & 5.5 & & 14.3 & \\
\hline At least once a week & 9.5 & & 10.1 & & 16.1 & & 4.7 & & 10.3 & \\
\hline Physical activity & & & & & & & & $<0.05$ & & \\
\hline 2-7 days per week & 12.8 & & 9.3 & & 19.1 & & 5.1 & & 12.8 & \\
\hline $0-1.5$ days per week & 13.5 & & 11.8 & & 18.6 & & 8.1 & & 16.2 & \\
\hline Sedentary behaviour+ & & & & & & $<0.05$ & & $<0.05$ & & \\
\hline Low & 12.6 & & 8.5 & & 20.4 & & 4.2 & & 13.9 & \\
\hline High & 12.7 & & 10.4 & & 16.1 & & 7.8 & & 13.0 & \\
\hline \multicolumn{11}{|l|}{$\begin{array}{l}\text { Consumption of fruits/ } \\
\text { vegetables+ }\end{array}$} \\
\hline Low & 11.9 & & 10.2 & & 19.1 & & 5.5 & & 14.6 & \\
\hline High & 13.2 & & 8.4 & & 19.1 & & 5.2 & & 12.4 & \\
\hline $\begin{array}{l}\text { Consumption of } \\
\text { sweets/soft drinks+ }\end{array}$ & & $<0.05$ & & & & $<0.05$ & & & & \\
\hline Low & 10.8 & & 10.3 & & 17.4 & & 5.6 & & 14.9 & \\
\hline High & 14.5 & & 8.3 & & 22.3 & & 5.0 & & 11.6 & \\
\hline $\begin{array}{l}\text { Having breakfast } \\
\text { every school day }\end{array}$ & & & & & & $<0.05$ & & $<0.05$ & & \\
\hline Not every day & 12.0 & & 11.2 & & 16.2 & & $7.2^{*}$ & & 14.6 & \\
\hline Every day & 12.5 & & 8.9 & & 20.7 & & 4.3 & & 12.9 & \\
\hline Weight control behaviour & & $<0.05$ & & $<0.05$ & & $<0.05$ & & $<0.05$ & & \\
\hline No & 13.1 & & 7.4 & & 21.4 & & 3.9 & & 13.2 & \\
\hline Yes & 4.7 & & 32.2 & & 8.5 & & 12.5 & & 16.0 & \\
\hline Being bullied & & & & $<0.05$ & & & & $<0.05$ & & \\
\hline Rarely / never & 12.7 & & 9.0 & & 19.0 & & 4.5 & & 13.1 & \\
\hline $\begin{array}{l}\text { more than } 2 \text { times } \\
\text { a month }\end{array}$ & 12.1 & & 13.2 & & 19.5 & & 16.6 & & 16.8 & \\
\hline
\end{tabular}

+ see method section for scale definition

* chi-square test within gender (remaining weight categories recoded into a joint category); effect not significant when no $p$-values are given

\# chi-square test comparing respondents with missing and non-missing values

tal occupational status, low family affluence, weight control behaviour, and having been bullied at least once a week were more frequently associated with being overweight in both genders. Having a single parent family, two or more friends of same sex, high levels of sedentary behaviour, having breakfast irregularly and low physical activity were more frequent only in overweight girls. In contrast, having a high number of friends of the opposite sex, a low level of adjustment to school, younger age, and dieting behaviour were all associated with the underweight category in both genders. High occupational status of the parents and high levels of classmate support were associated with being underweight in boys but not in girls. On the other hand, low sedentary behaviour and regularly having breakfast were frequently reported only in girls who were underweight.
Factors associated with over- and underweight in multivariable regression

In a multiple regression analysis we found a significant positive association between overweight and sedentary behaviour and a negative association between family affluence and overweight (Table 2). Dieting was used to control for the possible modification of food consumption in overweight pupils; this removed the negative association between consumption of sweets/soft drinks and being overweight. There was no interaction between any of the assessed risk factors and age or gender, apart from the interaction between being bullied and gender. Girls who were bullied at school had an odds ratio of more than 10 (calculated from the odds ratios for girls bullied at school versus not bullied boys (4.5) and girls not bullied at 
Table 2. Factors associated with overweight and/or underweight among 11- to 17-year old German students in multiple multinomial regression (odds ratios and $95 \%$ confidence interval).

\begin{tabular}{|c|c|c|c|}
\hline Variable & Overweight & Underweight & Missing BMI \\
\hline \multicolumn{4}{|l|}{ Sedentary behaviour } \\
\hline High vs. low & $1.37(1.06-1.77)$ & $0.92(0.76-1.10)$ & $1.20(1.00-1.45)$ \\
\hline \multicolumn{4}{|l|}{ Consumption of sweets/soft drinks } \\
\hline High vs. low & $0.87(0.68-1.12)$ & $1.51(1.27-1.80)$ & $0.81(0.67-0.98)$ \\
\hline \multicolumn{4}{|l|}{ Parental occupation } \\
\hline low vs. middle & $0.89(0.62-1.28)$ & $0.78(0.63-0.97)$ & $1.21(0.93-1.56)$ \\
\hline low vs. high & $1.21(0.85-1.74)$ & $0.72(0.57-0.92)$ & $1.31(0.99-1.73)$ \\
\hline \multicolumn{4}{|l|}{ Family affluence } \\
\hline Middle vs. low & $0.80(0.60-1.06)$ & $1.25(0.99-1.57)$ & $1.02(0.81-1.28)$ \\
\hline high vs. low & $0.53(0.38-0.75)$ & $1.24(0.97-1.58)$ & $0.90(0.70-1.15)$ \\
\hline \multicolumn{4}{|l|}{ Dieting } \\
\hline yes vs. no & $3.82(2.90-5.03)$ & $0.39(0.28-0.56)$ & $1.16(0.91-1.49)$ \\
\hline \multicolumn{4}{|l|}{ Grade } \\
\hline 7 vs. 5 & $1.15(0.85-1.57)$ & $0.85(0.70-1.04)$ & $0.56(0.45-0.69)$ \\
\hline 9 vs. 5 & $1.15(0.84-1.57)$ & $0.51(0.41-0.63)$ & $0.42(0.34-0.53)$ \\
\hline \multicolumn{4}{|l|}{ Regions } \\
\hline Saxony vs. Hesse & $0.98(0.64-1.52)$ & $0.60(0.43-0.84)$ & $0.18(0.11-0.29)$ \\
\hline Berlin vs. Hesse & $1.07(0.68-1.70)$ & $0.97(0.69-1.36)$ & $0.30(0.19-0.47)$ \\
\hline Northrhine-Westphalia vs. Hesse & $1.08(0.78-1.50)$ & $1.12(0.90-1.40)$ & $0.93(0.76-1.15)$ \\
\hline \multicolumn{4}{|c|}{ Interaction between gender and being bullied } \\
\hline \multicolumn{4}{|c|}{ Girls } \\
\hline Being bullied & $4.50(3.39-5.61)$ & $1.24(0.19-2.29)$ & $1.87(0.88-2.87)$ \\
\hline Not bullied & $0.43(0.32-0.57)$ & $1.77(1.48-2.13)$ & $1.26(1.04-1.53)$ \\
\hline \multicolumn{4}{|l|}{ Boys } \\
\hline Being bullied & $1.27(0.82-1.96)$ & $1.28(0.69-2.37)$ & $1.14(0.76-1.72)$ \\
\hline Not bullied (reference) & 1 & 1 & 1 \\
\hline
\end{tabular}

school versus boys not bullied at school (0.43)) for overweight compared with non-bullied girls, whereas the association was much weaker in boys. Being underweight was negatively associated with higher grades and higher parental occupation; it also differed across regions. Being bullied had no significant association with being underweight. Several other variables (included in Table 1, but omitted in Table 2) that showed significant bivariate relationships had no significant association with any of the weight categories in the multivariable model.

\section{Discussion}

Prevalence of overweight (for age and sex specific cut-off points) was lower than the nominal value of $10 \%$ in the normative sample for German adolescents ${ }^{19}$, whereas the prevalence of underweight was considerably higher, especially in girls. There was a substantial fraction of missing values for reported weight and height with differences across regions of Germany (the proportion of missing BMI was much larger in West German than in East German regions), which sug- gests some cultural or organisational differences. The higher proportion of missing information was accompanied by a higher proportion of underweight, especially among girls. In the Welsh HBSC sample the prevalence of overweight would have been higher by about $5 \%$ if measured data instead of self-reported were evaluated ${ }^{28}$, but the analysis included only adolescents who reported BMI. The discrepancy between international comparisons in estimates of the prevalence of overweight in school-age children based on normative samples and HBSC datasets has been discussed in length by Lissau $^{29}$. Our results suggest that additionally the potential impact of missing BMI information needs to be evaluated. The effects of missing responses and underreporting of weight and over-reporting of height may differ across countries and genders.

Our results support findings from previous studies which showed strong and consistent relationships between various measures of socioeconomic status and being overweight in adolescence ${ }^{12-14,30-32}$. Others found parental obesity as a risk factor $^{33}$, or social support and encouragement of physical activity as protective factors ${ }^{34,35}$. Both aspects are likely to be 
related to parental socioeconomic status. Differential underreporting of weight could play an additional role when social desirability is stronger in higher socioeconomic groups. Nevertheless, the finding that family affluence was still associated with overweight after adjusting for so many covariates in our analysis points to the high relevance of socioeconomic status for overweight among adolescents.

Sedentary behaviour was found to be associated with overweight in several longitudinal studies ${ }^{5,11,36,37}$ and this association is supported by the evidence from intervention studies $^{38,39}$. However, associations between sedentary behaviour and being overweight observed in cross-sectional studies may not have arisen from the causal effect of the sedentary behaviour itself, but rather, from an increase in sedentary behaviour due to being overweight ${ }^{40}$.

Being bullied is seen more often as a consequence of overweight ${ }^{6,10,11}$; however, bullying can also aggravate weight problems through social isolation ${ }^{6,41}$. The strong difference of the association between being bullied and weight categories by gender found in our study could be caused by gender differences regarding perception of body weight ${ }^{41}$. After adjusting for other variables (including being bullied) we did not find any association between social support (from friends, parents or classmates) and being overweight.

Apart from family affluence, sedentary behaviour, and being bullied (in girls) none of the potential behavioural, psychosocial or socioeconomic factors proposed to affect weight problems were associated with a higher risk of overweight in our analysis. Consumption of sweets and soft drinks displayed an opposite relationship with overweight than the theoretically postulated one. Since consumption of sweets is traditionally strongly associated with overweight, it might be most exposed to social desirability bias. More factors were associated with risk for overweight in bivariate analysis, but after controlling for other variables, the associations were no longer significant. The lack of independent association with the outcome can either mean that the bivariate association resulted from confounding or that there is an indirect association mediated by any of the variables included in the multivariable model.

\section{Limitations}

The results are not representative for Germany, since only four regions were selected for the study and within the regions only one third of the invited schools participated. A major limitation is that all variables were self-reported and thus exposed to different forms of bias. As stated by Elgar et al. ${ }^{28}$, self-reported body weight and height are important measures in epidemiological research, but the possibility of differential reporting across weight categories, genders, ethnic groups, regions and countries should be ruled out prior to comparisons.

In conclusions, whereas cross-sectional studies cannot establish causal relationships, we aimed to identify associations, which persist in a cross-sectional study after adjusting for other variables. We investigated a wide range of variables potentially associated with weight, including age and gender, measures of parental socioeconomic status, measures of social support and social stress as well as several documented behavioural factors. Many of the factors were significantly associated with being overweight in the bivariate analysis. But in the multivariable analysis, only three factors were associated with being overweight: sedentary behaviour, being bullied and family affluence. These results suggest that preventive strategies which target overweight and obese students from lower socio-economic backgrounds may effectively tackle weight problems.

\section{References}

1. Ebbeling CB, Pawlak DB, Ludwig DS. Childhood obesity: public-health crisis, common sense cure. Lancet 2002;360(9331):473-82.

2. Flegal KM, Troiano RP. Changes in the distribution of body mass index of adults and children in the US population. Int J Obes Relat Metab Disord 2000;24(7):807-18.

3. Andersen RE, Crespo CJ, Bartlett SJ, Cheskin LJ, Pratt M. Relationship of physical activity and television watching with body weight and level of fatness among children: results from the Third National Health and Nutrition Examination Survey. Jama 1998;279(12):938-42.
4. Janssen I, Katzmarzyk PT, Boyce WF, et al. Comparison of overweight and obesity prevalence in school-aged youth from 34 countries and their relationships with physical activity and dietary patterns. Obes Rev 2005;6(2):123-32.

5. Hancox RJ, Poulton R. Watching television is associated with childhood obesity: but is it clinically important? Int J Obes 2006;30(1): $171-5$.

6. Janssen I, Craig WM, Boyce WF, Pickett W Associations between overweight and obesity with bullying behaviors in school-aged children. Pediatrics 2004;113(5):1187-94.
7. Lowry R, Wechsler H, Galuska DA, Fulton JE, Kann L. Television viewing and its associations with overweight, sedentary lifestyle, and insufficient consumption of fruits and vegetables among US high school students: differences by race, ethnicity, and gender. J Sch Health 2002;72(10):413-21.

8. Robinson TN. Television viewing and childhood obesity. Pediatr Clin North Am 2001;48(4):1017-25.

9. Janssen I, Katzmarzyk PT, Boyce WF, King MA, Pickett W. Overweight and obesity in Canadian adolescents and their associations with dietary habits and physical activity patterns. JAdolescHealth 2004;35(5):360. 
10. Eisenberg ME, Neumark-Sztainer D, Story M. Associations of weight-based teasing and emotional well-being among adolescents. Arch Pediatr Adolesc Med 2003;157(8):733-8.

11. Elgar FJ, Roberts C, Moore L, Tudor-Smith C. Sedentary behaviour, physical activity and weight problems in adolescents in Wales. Public Health 2005;119(6):518-24.

12. O'Dea JA, Caputi P. Association between socioeconomic status, weight, age and gender, and the body image and weight control practices of 6- to 19-year-old children and adolescents. Health Educ Res 2001;16(5):521-32.

13. Batty GD, Leon DA. Socio-economic position and coronary heart disease risk factors in children and young people. Evidence from UK epidemiological studies. Eur J Public Health 2002;12(4):263-72.

14. Goodman E. The role of socioeconomic status gradients in explaining differences in US adolescents' health. Am J Public Health 1999;89(10):1522-8.

15. Treiber F, Harshfield G, Davis H, Kapuku G, Moore D. Stress responsivity and body fatness: links between socioeconomic status and cardiovascular risk factors in youth. Ann N Y Acad Sci 1999;896:435-8.

16. Currie C, Roberts C, Morgan A, et al. eds. Young people's health in context - Health Behaviour in School-aged Children (HBSC) study: International report from the 2001/02 survey. Kopenhagen: WHO-Europe; 2004.

17. Currie C, Samdal O, Boyce WF, eds. Health Behaviour in School-aged Children: a WHO Cross-National Study (HBSC), Research Protocol for the 2001/2002 Survey. Edinburgh: University of Edinburgh, Child and Adolescent Health Research Unit (CAHRU); 2001.

18. Richter M. Anlage und Methode des Jugendgesundheitssurvey. In: Hurrelmann K, Melzer W, Ravens-Sieberer U, ed. Jugendgesundheitssurvey - Internationale Vergleichsstudie im Auftrag der Weltgesundheitsorganisation WHO. Weinheim: Juventa; 2003:9-18.

19. Kromeyer-Hauschild K, Wabitsch M, Kunze $\mathrm{D}$, et al. Perzentile für den Body-mass-Index für das Kindes- und Jugendalter unter Heranziehung verschiedener deutscher Stichproben. Monatsschr Kinderheilkd 2001;149(8):807-18.

20. Currie CE, Elton RA, Todd J, Platt S. Indicators of socioeconomic status for adolescents: the WHO Health Behaviour in School-aged Children Survey. Health Educ Res 1997;12(3):385-97.
21. Boyce W, Dallago L. Socio-economic inequalities. In: Currie C, Roberts C, Morgan A, et al., eds. Young people's health in context - Health Behaviour in School-aged Children (HBSC) study: International report from the 2001/02 survey. Kopenhagen: WHO-Europe; 2004:13-25.

22. Prochaska JJ, Sallis JF, Long B. A physical activity screening measure for use with adolescents in primary care. Arch Pediatr Adolesc Med 2001;155(5):554-9.

23. Roseman MG, Yeung WK, Nickelsen J. Examination of weight status and dietary behaviors of middle school students in Kentucky. J Am Diet Assoc 2007;107(7):1139-45.

24. Utter J, Scragg R, Schaaf D, Fitzgerald E, Wilson N. Correlates of body mass index among a nationally representative sample of New Zealand children. International Journal of Pediatric Obesity 2007;1:1-10.

25. Batista-Foguet JM, Fortiana J, Currie C, Villabí JR. Socio-economic indexes in surveys for comparisons between countries. Social Indicators Research 2004;67:315-32.

26. Grittner U, Bloomfield K, Kramer S, Kuntsche S, Gmel G. Die Konstruktion eines empirisch bestimmten Sozialschichtindexes mittels optimaler Skalierung am Beispiel von Deutschland. Gesundheitswesen 2006;68(2):116-22.

27. Vyas S, Kumaranayake L. Constructing socio-economic status indices: how to use principal components analysis. Health Policy Plan 2006;21(6):459-68.

28. Elgar FJ, Roberts C, Tudor-Smith C, Moore L. Validity of self-reported height and weight and predictors of bias in adolescents. J Adolesc Health 2005;37(5):371-5.

29. Lissau I. Overweight and obesity epidemic among children. Answer from European countries. Int J Obes Relat Metab Disord 2004;28 Suppl 3:S10-5.

30. Romon M, Duhamel A, Collinet N, Weill J. Influence of social class on time trends in BMI distribution in 5-year-old French children from 1989 to 1999. Int J Obes Relat Metab Disord 2005;29(1):54-9.

31. Haas JS, Lee LB, Kaplan CP, Sonneborn $\mathrm{D}$, Phillips KA, Liang SY. The association of race, socioeconomic status, and health insurance status with the prevalence of overweight among children and adolescents. Am J Public Health 2003;93(12):2105-10.

32. Langnase K, Mast M, Muller MJ. Social class differences in overweight of prepubertal children in northwest Germany. Int J Obes Relat Metab Disord 2002;26(4):566-72.
33. Mamun AA, Lawlor DA, O‘Callaghan MJ, Williams GM, Najman JM. Family and early life factors associated with changes in overweight status between ages 5 and 14 years: findings from the Mater University Study of Pregnancy and its outcomes. Int J Obes Relat Metab Disord 2005;29(5):475-82.

34. Baba R, Iwao N, Koketsu M, Nagashima M, Inasaka H. Risk of obesity enhanced by poor physical activity in high school students. Pediatr Int 2006;48(3):268-73.

35. Springer AE, Kelder SH, Hoelscher DM. Social support, physical activity and sedentary behavior among 6th-grade girls: a cross-sectional study. Int J Behav Nutr Phys Act 2006;3:8.

36. Marshall SJ, Biddle SJ, Gorely T, Cameron $\mathrm{N}$, Murdey I. Relationships between media use, body fatness and physical activity in children and youth: a meta-analysis. Int J Obes Relat Metab Disord 2004;28(10):1238-46.

37. Hancox RJ, Milne BJ, Poulton R. Association between child and adolescent television viewing and adult health: a longitudinal birth cohort study. Lancet 2004;364(9430):257-62.

38. Atlantis E, Barnes EH, Singh MA. Efficacy of exercise for treating overweight in children and adolescents: a systematic review. Int J Obes 2006;30(7):1027-40.

39. Muller MJ, Asbeck I, Mast M, Langnase K, Grund A. Prevention of obesity - more than an intention. Concept and first results of the Kiel Obesity Prevention Study (KOPS). Int J Obes Relat Metab Disord 2001;25 Suppl 1:S66-74.

40. Kettaneh A, Oppert JM, Heude B, et al. Changes in physical activity explain paradoxical relationship between baseline physical activity and adiposity changes in adolescent girls: the FLVS II study. Int J Obes Relat Metab Disord 2005;29(6):586-93.

41. Fonseca H, Gaspar de Matos M. Perception of overweight and obesity among Portuguese adolescents: an overview of associated factors. Eur J Public Health 2005;15(3):323-8.

Address for correspondence
Dr. Matthias Richter, PhD
University of Bielefeld
School of Public Health
P.O. Box 100131
33501 Bielefeld
Germany
Tel: +49 521 1063878
Fax: +49 521 1066433
E-mail: matthias.richter@ uni-bielefeld.de

